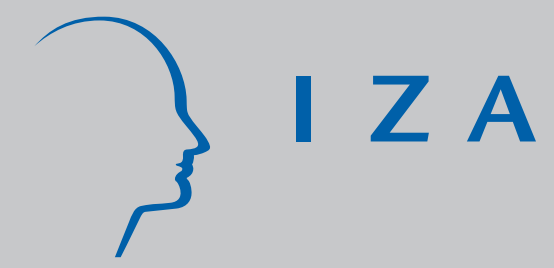

IZA DP No. 1194

Intergenerational Effects in Sweden:

What Can We Learn from Adoption Data?

Anders Björklund

Mikael Lindahl

Erik Plug

J une 2004 


\title{
Intergenerational Effects in Sweden: What Can We Learn from Adoption Data?
}

\author{
Anders Björklund \\ SOFI, Stockholm University \\ and IZA Bonn \\ Mikael Lindahl \\ SOFI, Stockholm University \\ and IZA Bonn \\ Erik Plug \\ University of Amsterdam, \\ Tinbergen Institute and IZA Bonn
}

Discussion Paper No. 1194
June 2004

IZA

P.O. Box 7240

53072 Bonn

Germany

Phone: +49-228-3894-0

Fax: +49-228-3894-180

Email: iza@iza.org

Any opinions expressed here are those of the author(s) and not those of the institute. Research disseminated by IZA may include views on policy, but the institute itself takes no institutional policy positions.

The Institute for the Study of Labor (IZA) in Bonn is a local and virtual international research center and a place of communication between science, politics and business. IZA is an independent nonprofit company supported by Deutsche Post World Net. The center is associated with the University of Bonn and offers a stimulating research environment through its research networks, research support, and visitors and doctoral programs. IZA engages in (i) original and internationally competitive research in all fields of labor economics, (ii) development of policy concepts, and (iii) dissemination of research results and concepts to the interested public.

IZA Discussion Papers often represent preliminary work and are circulated to encourage discussion. Citation of such a paper should account for its provisional character. A revised version may be available on the IZA website (www.iza.org) or directly from the author. 
IZA Discussion Paper No. 1194

June 2004

\section{ABSTRACT}

\section{Intergenerational Effects in Sweden: What Can We Learn from Adoption Data?*}

We explore the adoption data approach to estimating causal effects of parental education and income on the same outcomes of their children. Thanks to a data set drawn from Swedish population registers with detailed information on biological background and history of adoptees, we can test basic assumptions that the adoption strategy relies on. We find that the adoption method survives these tests surprisingly well. Our empirical results suggest that one more year of either mother's or father's education raises children's education by about 0.1 year. Our estimated income elasticities are around 0.1 .

JEL Classification: $\quad$ I20, J30, J62

Keywords: intergenerational effects, income, education, adoption data

Corresponding author:

Anders Björklund

SOFI

Stockholm University

10691 Stockholm

Sweden

Email: anders@sofi.su.se

\footnotetext{
* We thank Helena Holmlund and numerous seminar participants for useful comments on previous versions of the paper. Financial support from the Swedish Council for Working Life and Social Research (FAS) is gratefully acknowledged.
} 
Researchers from many academic disciplines have for long found adopted children an interesting group to study. Such children, especially when they have lived most of their lives with their adoptive parents, share their adoptive parents' and siblings' environmental influences but not their genetic ones. Thus, it has been argued, the study of adoptees can help researchers to disentangle genetic ("nature") and environmental ("nurture") influences on various outcomes.

Data on adoptees have been used in at least two different ways to learn about nature and nurture influences. One approach has been to allocate the total variance of an outcome into genetic and environmental components. In psychology, epidemiology and behavioral genetics, there is a long tradition to examine outcomes like diseases, personality traits and IQ in such a way. ${ }^{1}$ The correlation among family members who are related by adoption can, under some assumptions, be used to estimate the variation in the outcome that is explained by environmental factors that are shared by the family members.

Another approach can be typified with the recent studies by Sacerdote $(2000,2002)$, Plug \& Vijverberg $(2003,2004)$ and Plug $(2004) .^{2}$ These studies use a regression framework to estimate the causal impact of parental resources like schooling on a similar

\footnotetext{
${ }^{1}$ Other approaches use data on twins, adopted siblings or a combination of the two (twins reared-apart) to decompose the variation in an outcome into genetics and environment or combine data on twins and adoptees (twins reared-apart). Many of these twin and adoption studies are summarized in Brody (1992) who explicitly structures his chapter on "Behavior Genetics of Intelligence" into twin and family (adoption) studies. Also labor economists have studied the influences of nature and nurture on education and earnings using variance decomposition techniques using twins (Taubman 1976; Behrman et al. 1977) and using twins as well as adopted siblings (Björklund, Jäntti \& Solon 2004). Goldberger (1979) and Kamin \& Goldberger (2002) forcefully criticize much of the research following these approaches. They emphasize the crucial assumption that children reared apart are randomly assigned to adoptive parents, but they also question whether the allocation of variance to genetic and environmental components provides meaningful information at all.

${ }^{2}$ See also Scarr and Weinberg (1978), Dearden et al. (1997), Björklund \& Richardson (2001) and Das \& Sjogren (2002) for more analysis along these lines.
} 
outcome for the offspring. Whereas the regression of children's schooling on their parents' schooling estimated on a representative population sample is likely to blend causal schooling effects and genetic effects, the same coefficient estimated on a sample of adoptees is purged of the genetic effects. Thus it might better reflect the causal schooling effect of interest.

Both these research approaches using adoptees impose the same assumptions about the adoption process, namely that $(a)$ adopted children and their adoptive parents are connected (more or less) randomly; (b) that children are adopted as babies; and (c) that the rather small and potentially quite special group of adoptees can be used to make inference about the whole population. These assumptions are questionable and deserve to be scrutinized.

In this study we examine the usefulness of adoption data for research purposes such as those described above. We use a large data set collected from Swedish population register data. It contains all children born in Sweden in 1962-1973 who were adopted by both parents. These data are unique in a number of ways. First, in contrast to most previous studies of adoptees, our data set is large, namely 8309 individuals. Even more, we have information about biological and adoptive parents as well as biological and adoptive siblings. With such data at our disposal, we can examine whether the adoption process was random with respect to individual characteristics like schooling and earnings. Further, and in contrast to many previous studies, we can determine quite accurately from census data when the children moved to their adoptive parents. Finally, the children are legally adopted by both parents so we can rule out such cases when one parent (usually the father) adopted a child that the spouse had from a previous relationship. 
We illustrate our analysis of the adoption approach with applications employing the second regression-based research approach described above. These applications are interesting in their own right. We use education as a family characteristic and our results contribute to the literature that addresses the question: does raising mothers' and fathers' education raise the educational level of the next generation? Such educational spillover effects are of obvious policy relevance as they provide information of one part of the social returns to education ignored by private return estimates derived from individual earnings equations. Intergenerational effects of human capital are also crucial in some versions of modern growth theory, see e.g. Benabou (1996) and Aghion \& Howitt (1998). We also use parental income and earnings as family characteristics. This literature adds to the rapidly rising literature on intergenerational income mobility, see Solon (1999).

The paper proceeds as follows. We describe the institutional setting of adoptions in Sweden during the period of our study as well as the data in section 1 . Section 2 discusses the basic assumptions underlying the adoption methodology and how we can test these assumptions within the framework of the regression approach. In section 3, we report estimates of parental education and income effects using models previously used in the literature. We get results quite similar to those in previous studies, namely much smaller effects of adoptive parents' education and earnings than of biological parents'. Nonetheless, our estimates of the impact of adoptive parents' characteristics are reasonably precise and statistically different from zero. In section 4, we perform the tests and find that they do not reject the adoption approach and section 5 concludes. 


\section{Institutions and data}

We use administrative register data from Statistics Sweden on all legal adoptions, i.e., adoptions confirmed by the public court and notified in the Swedish population register. In particular, our data set contains all persons who were born in Sweden between 1962 and 1973 and adopted by both parents. To understand the usefulness of this data set, we start in this section by describing the institutional rules governing adoptions in Sweden during this period of time. Then we describe the data set and the variables in some detail.

\subsection{Adoptions in Sweden 1962 - 1973}

Sweden has had an adoption law since 1918. To learn how the law was implemented by Swedish authorities during $1962-73$, we have used several sources. First, we used two Handbooks for social workers and authorities involved in adoption issues, Allmänna barnhuset $(1955,1969)$. They were authorized by the National Board of Social Affairs. The 1969 version was an updated version of the older one. ${ }^{3}$ A second source is an informative text book for adoptive parents, Asklund (1960). The author was a social worker by training, but also a well-known journalist with an own radio program on social issues. Finally, we have learnt much from Nordlöf (2001), which in much detail describes how adoptions took place in Stockholm municipality during 1918-1973. We have also benefited from an interview with Nordlöf. In the following we describe the law and the adoption administration as we understand they were implemented during 1962-1973.

The basic principle of the law, and strongly emphasized in all our sources, has always been that an adoption should be "to the best of the child". This means that the decision

\footnotetext{
${ }^{3}$ The National Board of Social Affairs also issued "advice and guidelines" that we have learnt from as well (Kungl. Socialstyrelsen 1959, 1968).
} 
whether an adoption should take place as well as the choice of adoptive parents should serve the interest of the child and not solve a problem for the couple that wanted to adopt.

A second important principle was that economic compensation between the adoptive and the biological parents (or their families) to the adoptive parents was not allowed. ${ }^{4}$ Because the period we consider was characterized as one with "excess demand" from prospective adoptive parents, payments to biological parents would probably have been more common if allowed. The adoption process should be cancelled if such payments were done.

A third principle for this period was that an adopted child in all legal respects (e.g., inheritance) had the same status as a biological child. Further, all formal connections with the biological parents were broken, e.g., the child could not inherit its biological parents.

The law also said how the adoption process should proceed. It said that a specific social authority, the barnavårdsnämnden, should be responsible for the process. Thus, mothers (and fathers) who wanted to adopt away a child should contact this authority as well as families who wanted to adopt. The legal adoption decision was taken by public court after being advised by the social authority.

Adoptions could take place in many different circumstances. In order to describe the formal process, we start with a typical case. Then we proceed with less common cases.

\section{The process in a typical case}

The vast majority of adoptions took place at an early age of the child. In a typical case, an unmarried pregnant woman considered adoption and therefore contacted the social

\footnotetext{
${ }^{4}$ The rule had one exception. The biological parents (or their families) could give a once-and for-all contribution to the child. This money must be administered by the social authority that gradually should forward the money to the adoptive parents. Our sources suggest that such payments were not common.
} 
authority. The authority allocated one social worker to the case, and this person became a key person in the adoption process.

The mother could not decide to adopt away a child until she had recovered from the delivery. The new-born child was therefore initially placed at a special nursery home. After recovery from the delivery, the mother had to sign a form saying that she accepted the adoption. This form did not name any prospective adoptive parents. An unmarried biological father had no formal say in the adoption process, but should be contacted on the issue and allowed to give his opinion. But quite often the father was unknown. Of our 8309 observations, 93 percent of the biological mothers were identified in the population register and 58 percent of the fathers.

The social authority could then start to work on the match between the child and prospective adoptive parents. When a suitable adoptive family had been found, the child was temporarily, and on trial, placed in this family as a foster child. The 1969 Handbook recommended that this placement should take place before age 6 months, but ages 7-8 months were not uncommon. A common reason for the delay was that the mother could not decide whether she wanted to adopt or not.

If the trial period turned out well, the next step for the prospective adoptive parents was to apply to the court for a legal adoption decision. The textbook for parents said that a trial period of at least three months was required before this application should be done. Nordlöf (2001) said that these trial periods often lasted around six months. This estimate probably includes the waiting time for the decision by the court. ${ }^{5}$

\footnotetext{
${ }^{5}$ According to our sources it was very rare that a child spent a trial period in one family and then eventually ended up as being adopted by another family.
} 
A complete adoption application to the court should contain both a formal request to adopt a specific child and a number of documents as addendums. In the formal request, the parents should present themselves and inform that they had taken care for the child for some time. It was also recommended that they declared that no economic compensation was involved in the adoption. The required documents were birth certificates for both the child and the adoptive parents. The child's birth certificate should contain information about the biological parents; if any of these (more often the father) was unknown the certificate should tell that this was the case. Another requirement was the formal adoption agreement by the biological mother (and sometimes the father).

The court was required by law to collect additional information about the adoption case. In particular, the court should ask for a recommendation by the social authority, which in turn was based on an investigation by the assigned social worker. This investigation was a key document in the whole process and the report was sent to the court as well. We discuss the content of the investigation in more details below.

For all these reasons, the adopted child could have spent quite long time with its new parents when the formal adoption decision was taken.

\section{Characteristics of biological mothers and fathers}

A common view of the biological mother is that she was young, unmarried and poor. Our Table 2 (see below), reporting descriptive statistics for all (known) biological parents to adopted children in Sweden born 1962-1973, indeed confirm that both biological mothers and fathers were younger than non-adopted children's parents. Nonetheless, there is quite much age variation among biological parents and only 29 percent of the mothers (and 7 
percent of the fathers) were teenagers when the child was born. Information on marital status is more meagre, but Nordlöf (2001) reports that 8 percent of biological mothers to adopted children born in Stockholm in 1960-73 were married.

Low income was a common reason to leave a child for adoption and Nordlöf (2001) reports that lower social classes were clearly overrepresented among biological mothers. One should note though, that the occupational data she used pertained mainly to women well below age 30 and it is well known that socio-economic status at such low ages does not strongly correlate with long-run status. Further, "shame" was also mentioned as a common reason for adoption. Thus, although we have reason to believe that most mothers had low income and low socio-economic status also in a long-run perspective, they were not necessarily a very homogenous group in these respects.

\section{Characteristics of the children}

Since the health status of the child was a major concern, the social worker should make sure that a careful medical examination of the child was done. The Handbooks devoted different space to the health issue. The 1955 version only said that the social worker should have a doctor examine the child before the final decision was to be taken by the court. The 1969 version, however, had a longer section about the child's mental and physical condition. The main focus is on genetic heredity of such conditions, and a main message of the text is to downplay the risk of inherited problems. In particular, it was stressed that alcoholism is not genetically inherited. However, a few severe mental problems (like Schizophrenia and depression) and some named physical problems were considered likely to be inherited. In such cases adoptions were not advised to take place. 
But the Handbook also stressed that a mental or physical problem not necessarily ruled out an adoption. In such cases, however, special care must be taken in choosing the best possible adoptive parents.

We have no evidence from our sources suggesting that children of one specific sex were more available for adoption than children of the other sex. This is not to be expected either, since in the typical case the child was considered for adoption before the biological parent(s) knew the sex of the child. Our sources, however, report that the demand for girls for adoption was higher than for boys.

\section{Characteristics of adoptive parents}

The responsible social worker should undertake a very careful investigation of prospective adoptive parents. A series of well-planned interviews in the home environment should take place to find out whether they were suitable as adoptive parents. Both Handbooks emphasized that economic resources and social status were not most important, although a reasonably "stable" economic situation was important. Further, the apartment should not be inconveniently small for the family and the child, since otherwise a stressful situation could occur. The 1969 version strongly argued that good adoptive parents should be tolerant, since an adopted child could get into problems and maybe not meet the expectations of its parents. In that case, a tolerant attitude of the parents would be crucial. Likewise, it was important to discover when prospective parents saw an adoption as a way of solving a problem of their own rather than getting a child that they really wanted to care for. "Normal people" are the best adoptive parents 
according to the 1969 Handbook. Nonetheless, due to these considerations, one would expect adoptive parents to be under-represented in the lower parts of these distributions.

The law required that the adoptive parents should be 25 years of age. (This rule did not apply to the special case of step-parent adoptions however.) There were no formal rules about an upper age limit but the adoptive parents were not supposed to be older than they could have been the biological parents of the child.

In contrast to some other countries, there was no requirement about the duration of the marriage. But other requirements made it unlikely that newly married couples would be able to adopt a child. For example, the social worker was supposed to find out that the prospective adoptive parents would not be able to get own biological children.

We searched the Handbooks for information about the attitude to working mothers and found the 1955 version to be explicit in this respect. Illustrated by a drawing showing a woman lovingly holding a young child, it said that families where the mother can stay home to care for the child, at least during the first years, should be given priority. The 1969 version, however, was completely silent about working mothers.

\section{The matching of the child and the parents}

From our methodological perspective, the central issue is how the matching of children (and thus biological parents) and adoptive parents took place. In particular, we want to know whether matching could be related to any characteristics that are correlated with our outcome variables of interest, namely earnings and education. Because the responsible social worker had access to quite much information about the biological parents (mostly the mother) and prospective adoptive parents, there was room for such 
systematic matching. In most cases, however, biological parents did not know anything about the adoptive parents, and adoptive parents only wanted to have limited information about the biological parents.

The fact that there was room for systematic matching does not imply that such matching actually took place to a significant extent. The main focus in the Handbooks was on guiding the social worker to find suitable adoptive parents in general. Indeed, the 1969 version said explicitly: “The social worker's ambition to find an adoptive home that fits a specific child particularly well is often unrealistic. The important task is to find good adoptive parents who can be expected to give children in general good conditions." (Own translation from Allmänna Barnhuset (1969, page 31).

Although the 1955 Handbook also focused on what are generally good adoptive parents rather than on good matches, it had a few sections that explicitly talked about matching. After having stressed that adoptive parents should have a good and stable income that generally exceeds that of the biological family, the Handbook also said that the standard of the adoptive family should not be so high that the child does not fit in, (Allmänna Barnhuset 1955, page 38). Then follows a section where the same statement is done about intellectual standards: “...although a stimulating environment can help develop any child, a too large gap between adoptive parents' talents and those of the adopted child might cause problems for the child". The motivation for this statement was that adoptive parents might become disappointed if the child does not meet the expectations of the adoptive parents. 
The 1955 Handbook mentioned that some attention should also be paid to physical attributes - like height and colour - of the adoptive parents and the biological parents. ${ }^{6}$ Too large differences in this respect could make the child look strikingly different from its parents, a fact that later in life might generate frequent annoying comments.

It has been suggested to us that matching by physical - and possibly also intellectual traits - probably was more important if the adopted child was supposed not to be informed about the fact that (s)he is adopted. On this issue our sources clearly recommended the adoptive parents to inform the child about its origin when it is old enough to understand such information; age four is mentioned as an upper age limit in both the 1955 Handbook and the textbook for parents.

A correlation among biological and adoptive parents' traits could also appear if these parents come from the same, or a similar, region. Nordlöf (2001) reports that 39 percent of all adopted children born 1960-73 in Stockholm municipality came to adoptive homes in the same municipality. Another 22 percent came to a neighbour municipality.

Our overall conclusion is that one cannot consider the matching of children and adoptive parents during the period 1962-1973 as the outcome of a random process. However, it is an open question whether the relevant correlation between the traits of the biological parents and those of the adoptive parents is strong enough to severely bias an estimator that assumes random matching of adoptees.

\footnotetext{
${ }^{6}$ This section is illustrated with a drawing of a black-haired child and two blond parents with the subtitle: "One should avoid placing a child with a typical South-European look among blond and tall parents".
} 


\section{Other cases of adoptions}

Although the adoption case described above seems to have been the most common one, there were also other cases. Some of these other cases required more or less the same careful investigations by social authorities as the typical case described above. For example, the same procedure applied when the biological parents were married, although in such cases both biological parents must accept the adoption. Our sources suggest that such adoptions took place because the biological parents were not able to take care of the child.

It could also happen that older children were adopted. A frequent case was when a foster child "grew into" the foster family so that the foster parents wanted to adopt the child. In such cases the formal procedure was slightly different.

Step-parent adoptions were yet another kind of adoption, namely such when the spouse of one biological parent adopted the latter's child. There were two cases of such adoptions and they show up in the population register data in different ways. One case was if one spouse had a child from a previous marriage that was adopted by the new spouse. Because such children are adopted by one parent only, they are not part of our basic data set. Another case of step-parent adoption was when one spouse brought to a new marriage an own child that was born outside of marriage. In such cases, the child could not formally be adopted by one new parent only. Instead it had to be adopted both by the biological parent who brought the child to the new relationship and the new spouse. Thus, it could be that some children who are adopted by two parents have one formal adoptive parent who also is a biological parent. From the data point of view, such cases are potentially problematic for us because those who are counted as an adoptive 
parent could also be a real biological parent. In our data set, we've found only 6 of such cases, which we eliminated in our analysis.

Adoptions could also take place within families, e.g., the parents of a young mother could adopt a child that would be their biological grandchild. Such cases would create severe problems for our study. We are confident, though, that such cases are extremely rare during the period that we consider. According to Nordlöf only four out of 1186 adoptions in Stockholm of children born 1960-73 were done by relatives. Although Stockholm might not be fully representative in this respect, we do not believe that such within-family adoptions are common in our data set.

Single parents were legally allowed to adopt, but our sources show that such cases were extremely rare. In any case, our data only contain children adopted by both a mother and a father.

\subsection{The data set}

Because of the adoption process described above, the Swedish population register contains information about both adoptive and the known biological parents. Adoption age is, however, imprecisely measured in the register data so we use information from the censuses in (November) 1965, 1970, 1975, 1980, 1985 and 1990 to figure out in what household the adopted child lived at a certain period of time. By combining this information with data on the adopted child's month and year of birth, we compute lower and upper bounds on the age at which an adopted child started to live with the adoptive 
parents. ${ }^{7}$ We take the average and subsequently call this variable "adoption age" (see note to table 1).

From the population register, we also have access to the adopted children's siblings, both on their biological parents' side (our data distinguish between full and half siblings) and on their adoptive parents' side. On the latter side, there could be both siblings who also are adopted and siblings who are biological children of the adoptive parents.

Further, we use other registers to get information about parental characteristics and child outcomes at adult age. We use the 1970 census and the 1990 version of Statistics Sweden's special education register (utbildningsregistret) to get information about biological and adoptive parents' education. ${ }^{8}$ The 1970 Census, upon which the 1990 version is built, contains detailed education information, which is available in terms of very detailed classifications into field and level of education. Beginning with primary school, obligatory at 6 or 7 years of age, we distinguish seven levels with a corresponding total number of years: primary education ( 7 years), lower secondary education ( 9 years), short and long upper secondary education (11 and 12 years), short and long university (14 and 15.5 years), and $\mathrm{PhD}$ (19 years).

We use tax-register data to get parental income and earnings for 1970, 1975, 1980, 1985 and 1990. Earnings include income from work including self-employment and sickness benefits. Income includes earnings, but also some taxable transfers like UIbenefits and pensions as well as capital income and realized capital gains. We distinguish between father's income and earnings and the family's (both father's and mother's)

\footnotetext{
${ }^{7}$ About 80 percent of the adoptees are likely to have been adopted within 1 year. This was checked by looking only at those adoptees born within a year prior to the censuses in 1965 and 1970.

${ }^{8}$ We use the education register dated 1990 to obtain parental education measures. If not available, we use the 1970 register instead. The reason for doing so is that some parents were quite young in 1970 .
} 
income and earnings. Our intergenerational income and earnings analysis follows previous literature in economics and focuses on the impact of long-run parental income and earnings on offspring's outcomes. Thus, we use average parental income (and earnings) taken over a 20 year period running from 1970 to $1990 .^{9}$

We measure children's outcome in the 1990s, also using administrative register data. Education information comes from the 1999 version of the education register. ${ }^{10}$ Thus, the youngest children born in 1973 were at least 26 years of age when we measure this outcome variable. We use a dummy variable for at least short college education as outcome variable and this variable is taken directly from the register. We also use years of schooling, which we infer from the information in the education register.

Children's annual income and earnings data also stem from administrative registers, which in turn have been created by information from compulsory tax reports from employers. We use annual income and earnings from 1999. The definitions of income and earnings are the same as for parents even though we use single-year outcomes for children.

Table 1, column I, reports our data set of all children adopted by both parents during 1962-1973. The total number was stable around 1100 children per year during the first three years, but then started to decline quite dramatically. A new abortion law, effective from 1963 onwards, and more efficient birth control are the most likely explanations of the decline. Because there was an "excess demand" for children to adopt already before

\footnotetext{
${ }^{9}$ More specifically, we first exclude those observations in which annual income (or earnings) is missing, below 1000 dollars, or obtained when parents were younger than 30 or older than 60 . With annual income and earnings measures measured in logarithms, we then take averages.

${ }^{10}$ In fact, we use the maximum level achieved in the 1990, 1993, 1996 or 1999 education registers.
} 
this decline, it is not surprising that $1962-73$ was the period when international adoptions became more frequent, see Björklund \& Richardson (2001).

Our analysis samples are smaller than the 8309 observations in Table 1. In all analyses we impose a set of age restrictions pertaining to the adopted child and its adoptive parents, see column II for details. These restrictions reduce the number of observations to 7668 , or by some eight percent. Further, the education analysis requires that both child and parental education data are available. This requirement reduces the number of observation from 7668 to 7498 , or around 2 percent. Similarly, the income analysis requires that child and parental income data are available. In this analysis we also require that we observe the child's income at age 30 or older. The motivation is that we want to estimate the impact on long-run income, and the association between annual and long-run income is weak before age 30 . As a consequence of this age requirement, the income analysis is based on 5901 observations, which amount to an 8.5 percent non-response rate compared to the 6451 observations with valid age data.

\subsection{Descriptive statistics}

Table 2 reports the means and standard deviations of the main variables that we use in our analysis. We report such descriptive statistics for our sample of adoptees and for a random sample of non-adopted children born in Sweden. The random sample is drawn to create the same cohort distribution as in the adoptee sample.

The table's first panel shows that adopted children are quite similar to the random sample of non-adopted and same-aged children when it comes to the outcome variables used in our study. There are some small differences, however, and they consistently show 
that adopted children did slightly worse: years of schooling is about 0.3 years lower, the percentage with college education is 0.09 compared to 0.13 , earnings is 0.09 log points lower and income is $0.07 \log$ points lower.

The second panel compares the characteristics of non-adopted and adopted children's birth parents. These differences are larger. Non-adopted children's birth fathers have 0.79 more years of schooling than adopted children's fathers. The corresponding difference for mothers is 0.57 . College education is also more frequent among non-adopted children's birth parents than among adopted children's birth parents. The earnings and income differentials are in the range 0.29 to 0.53 log points. Further, adopted children's birth parents are 2-3 years younger at the birth of the child than non-adopted children's birth parents. The fraction of teenage parents is also considerably higher among adopted children. We also note that there is more variation in the age of adopted children's birth parents than in the age of non-adopted children's birth-parents. Finally, despite the mean differences between non-adopted and adopted birth-parents, the standard deviations show that there is quite much overlap (common support) in the two distributions.

The third panel of Table 2 reports characteristics of adoptive parents. Comparing with adopted children's birth parents, we find quite substantial differences, especially for father's characteristics. Average years of schooling are 1.41 higher, incidence of college education is 0.12 higher, earnings and income are around $0.45 \log$ points higher. Average family earnings and income are also quite much higher -0.60 log points - for adoptive parents than for the birth parents. The age differentials are as large as 7.5 years for fathers and 9 years for mothers. These age differentials, in turn, probably account for some of the earnings and income differentials. In our subsequent analysis we control for these age 
differentials. For these two parental distributions as well, the standard deviations show that, despite the mean differences, there is a considerable overlap.

We have also computed similar descriptive statistics (available upon request) for three more restrictive samples that we use in our analysis, namely (i) a sample with children born 1962-65, (ii) the "income sample" we use below, and (iii) the sample with valid observations for both birth mothers and birth fathers. The general patterns for the full sample in Table 2 can also be found in these sub-samples.

\section{A simple intergenerational effect model}

We use the following model of the intergenerational causal transmission of an outcome, $Y$, from parent $p$ to child $c$ in family $i$

$$
Y_{i}^{c}=\alpha+\beta Y_{i}^{p}+g_{i}^{p}+f_{i}^{p}+v_{i}^{c}
$$

where $g_{i}^{p}$ represents the unobserved endowment that is passed on genetically from parent to child; $f_{i}^{p}$ is the unobserved parent specific endowment that is independent of genes and expresses, among others, child-rearing talent; and $v_{i}^{c}$ is a child-specific characteristic.

The corresponding model for a child adopted into family $i$ is

$$
Y_{i}^{a c}=\alpha^{a}+\beta^{a} Y_{i}^{a p}+g_{j}^{b p}+f_{i}^{a p}+v_{i}^{a c},
$$

where $Y_{i}^{a c}$ and $Y_{i}^{a p}$ are the adopted child's and the adoptive parent's outcome; $g_{j}^{b p}$ is the unobserved heritable endowment coming from the adopted child's biological parent denoted by $j ;{ }^{11} f_{i}^{a p}$ represents the child-rearing and cultural endowment of the adoptive parent; and $v_{i}^{a c}$ is the unobserved characteristics of the adopted child. The error terms

11 Note that $g^{p}, f^{p}, g^{b p}, f^{a p}$ all are normalized as to have a coefficient equal to one. 
$v_{i}^{c}$ and $v_{i}^{a c}$ come from different distributions, where the latter includes unobserved

environmental effects that may depend on experiences in the womb, the separation from the biological mother, and the quality of nursery homes.

Below, we discuss the necessary assumptions to estimate causal intergenerational effects using adoption data. We separate the discussion into those assumptions needed to consistently estimate the effect of parent's outcome on children's for adoptees in equation (2) and those assumptions needed to generalize this to the population of all children in equation (1). This distinction compares closely to the internal and external validity of the adoption approach.

Internal validity: the assumptions necessary to estimate $\beta^{a}$ consistently in equation (2)

To consistently estimate the intergenerational effect for adoptees using a sample of adoptees, we need to assume that (a) adoptees are randomly assigned to adoptive families; that (b) children are adopted at birth; and that (c) the parent's child-rearing talent and observed resources are unrelated.

The first but key assumption in almost all adoption applications is that when it comes to genetics children are randomly assigned to adoptive families, so that $\operatorname{cov}\left(Y_{i}^{a p}, g_{j}^{b p}\right)=0 .{ }^{12}$ The existence of non-random assignment likely generates an estimate

\footnotetext{
${ }^{12}$ Recent adoption studies in economics has not always directly tested this assumption. Plug and Vijverberg $(2003,2004)$ and Plug (2004) have no information on the assignment process. They explicitly assume random assignment to give their results a causal interpretation. Das and Sjogren (2002) use a small sample of adoptees in Minnesota. They are silent when it comes to random assignment, although their sample suffers from selective placements (De Fries and Plomin, 1978). Sacerdote (2000, 2002) uses two small samples of adoptees to test for selective placement. He finds no support, but due to the imprecision of his estimates non-random assignment cannot be ruled out. In a variance decomposition approach using nine sibling types, Björklund, Jäntti \& Solon (2004) tested the assumption indirectly by adding one parameter for the correlation in genetic endowment between siblings who are adopted and siblings who are not. The point estimate of the correlation was positive but insignificant and did change the results. In psychology the
} 
of the intergenerational coefficient $\beta^{a}$ that is too high since genetically advantageous children probably are assigned to genetically advantageous parents.

We deal with this in two ways. The first remedy for the missing heritable endowment $g_{j}^{b p}$ is to replace it with $Y_{j}^{b p}$ in our estimations. We test whether the outcome variable is uncorrelated among adoptive and biological parents, i.e., $\operatorname{cov}\left(Y_{i}^{a p}, Y_{j}^{b p}\right)=0$, and also whether including the outcome variable as a regressor in (2) does not affect the intergenerational estimate, i.e., $\hat{\beta}_{Y^{a p}}^{a}=\beta_{Y^{a p} Y^{b p}}^{\hat{a}}$. Second, we regress the outcome of the adoptive parents' biological child on the outcome of the adopted child's birth parents. The idea is that under random assignment we should observe no association between these children and parents. Any estimated effect would then come from selection, and demonstrate that these children and parents are somehow connected. ${ }^{13}$

The second assumption is that children move to their adoptive parents immediately at birth. If this is not the case, some children in our sample receive only part of the treatment $Y_{i}^{a p}$ and as a consequence the parameter $\beta^{a}$ will be underestimated. In our data we have approximate information about the age adoptees meet their adoptive families. We include this variable as a regressor in equation (2) as well as an interaction term of adoption age and the outcome variable of the adoptive parents. If this interaction term is insignificant, we cannot reject that the effect of adoptive parent's outcome is the same across adoptees entering the adoptive family at different ages. We also deal with this by focussing on a subsample of children adopted within the first 12 months of their lives.

assumption has been directly tested, mostly on outcomes such as intelligence test scores, but also on education and occupation. Many of these studies are old and in most cases the samples are very small. In general, positive selection has been found. For surveys, see Jencks (1972) and Brody (1992).

${ }^{13}$ We thank Alan Krueger who suggested this idea. 
The third assumption requires that the unobserved non-genetic characteristics of the adoptive parents (included in $f_{i}^{a p}$ ) and the outcome variable $Y_{i}^{a p}$ are unrelated. This is the only assumption we cannot test for. This means that throughout the paper we interpret $\beta^{a}$ as an estimate of the effect on the adopted child's outcome of the adoptive parent's outcome and everything else that is correlated with the adoptive parent's outcome and has an independent effect on $Y_{i}^{a c}$, net of the genetic transmission. We see this estimate as an upper bound estimate of the intergenerational causal effect of an outcome $Y$ assuming that the unobserved characteristics and observed outcome of the adopted parents are positively correlated. ${ }^{14}$

External validity: the assumptions necessary to interpret an estimate of $\beta^{a}$ in equation (2) as a consistent estimate of $\beta$ in equation (1)

The assumptions needed to interpret an intergenerational estimate using adoptees as representing that for the population of all children are that (a) parents do not treat their own-birth children ${ }^{15}$ differently from adopted children would they have been similar in any other way than their genetic link; that (b) the characteristics that make adoptees and their adoptive parents different from any other children and parents are not related to the adoptive parents' outcome; and that (c) our functional form is correct and that mobility across generations is indeed linear.

The first assumption requires treatment differentials to be absent. We might expect that adoptive parents, perhaps because of some evolutionary drive, invest relatively less

\footnotetext{
${ }^{14}$ Note that it is not a priori clear that the correlation is positive. If, for instance, some mothers with lower parenting skills would rather focus on work careers than on motherhood, the reverse would be true.

${ }^{15}$ We use the concept own-birth child for the case when a child was reared by its biological parents.
} 
in their adopted child than what they would have invested had they had a biological child. In the presence of such "Cinderella motives" (Case, Lin \& McLanahan, 2000) ${ }^{16}$ we would expect $\beta^{a}<\beta$. To test for this, we estimate separate regressions for adoptees with only siblings who also are adopted to the rearing parents, and for adoptees with only siblings that are biological children to the rearing parents. We expect the intergenerational estimate in the latter case to be smaller if these motives are present.

The second assumption deals with the similarities shared by adoptive and other parents. Since adoptive parents first select themselves (by showing a strong preference for parenthood) and are then selected by the adoption authority as being suitable parents, we might expect them to have, on average, better parenting skills than other parents. We test whether these skills are somehow related to the parental outcome $Y_{i}^{a c}$ by focussing on parents that raise both adopted and own-birth children. For these parents we may write the unobserved parent-specific endowment so that $f_{i}^{a p}=f_{i}^{p}+\eta_{i}^{a p}$, where $\eta_{i}^{a p}$ captures the child-rearing skills that are typical to adoptive parents. We then modify the original equation (1) for own-birth children such that

$$
Y_{i}^{c}=\alpha+\beta Y_{i}^{p}+g_{i}^{p}+f_{i}^{p}+v_{i}^{c}
$$

and

$$
Y_{i}^{c}=\alpha+\beta^{\prime} Y_{i}^{p}+g_{i}^{p}+f_{i}^{p}+\eta_{i}^{a p}+v_{i}^{c}
$$

where equation ( $\left(1^{\prime}\right)$ is for own-birth children (with at least one own-birth sibling and no sibling adopted into the family) and equation (3) is for own-birth children with parents that adopt and raise their own children as well. Assuming homogenous treatment effects $\left(\beta^{\prime}=\beta\right)$ the difference between the estimated parameters from (3) and (1') becomes:

\footnotetext{
${ }^{16}$ Note though that Case et al. use this term for stepchildren, not for adopted children.
} 


$$
p \lim \left[\hat{\beta^{\prime}}-\hat{\beta}\right]=\operatorname{cov}\left(Y_{i}^{p}, \eta_{i}^{a p}\right) / \operatorname{var}\left(Y_{i}^{p}\right)
$$

The generalizability of our adoption application requires that this expression equals 0 . It is easy to see that it is not necessary that adoptive and biological parents have the same parental skills, but only that the difference in (hypothetical) parental skill is unrelated to the outcome variable of the parent.

The second assumption is also whether adopted children are similar to other children in terms of unobservable characteristics. One might expect that adoptees are drawn from the pool of disadvantaged children, perhaps because of having inferior genes, or because of negative early environmental experiences that emerged either in the womb or during institutional caretaking. ${ }^{17}$ Own-birth children with full siblings that are adopted out form a reasonable group to test the impact of these unobservables. If we estimate mobility effects using this subsample, we indirectly isolate some of the unobservables that are typical to adoptees and thus for the bias that it entails. For own-birth children with full siblings that are adopted out we specify $v_{i}^{a c}=v_{i}^{c}+\omega_{i}^{a c}$, where the unobserved characteristics are portioned into a part that represents the characteristics typical to ownbirth children and a part that equals the characteristics the child would have had if adopted. These latter characteristics capture factors similar across biological siblings prior to adoption, such as similar environmental experiences very early in life and in the womb. ${ }^{18}$ Thus, for own-birth children with biological siblings (i.e., siblings who have the

\footnotetext{
${ }^{17}$ Such effects are likely much more important when using foreign adoptees, due to undernourished mothers in developing countries or poor institutions for children waiting to be adopted.

${ }^{18}$ For this test to be insightful we have to assume that biological children from families where at least one child is adopted out stay due to random events.
} 
same biological father and mother) adopted out (which is compared to the remaining sample), we can replace $v_{i}^{c}$ by $v_{i}^{a c}$ in (1) and rewrite the equation so that

$$
Y_{i}^{c}=\alpha+\beta^{\prime /} Y_{i}^{p}+g_{i}^{p}+f_{i}^{p}+v_{i}^{c}+\omega_{i}^{a c}
$$

Assuming homogenous treatment effects (that the intergenerational coefficients are the same for adoptees and non-adoptees), the difference between the estimated parameters from (4) and (1) is:

$$
p \lim \left[\hat{\beta^{\prime \prime}}-\hat{\beta}\right]=\operatorname{cov}\left(Y_{i}^{p}, \omega_{i}^{a c}\right) / \operatorname{var}\left(Y_{i}^{p}\right)
$$

We test whether the similarity assumption as stated earlier holds up by testing whether the difference between these two estimates is zero.

The third assumption on functional form we discuss later in the empirical section.

\section{Baseline results}

\subsection{The effects of parents' education: baseline results}

We first regress the education variables of the child on the same variables of their parents. Table 3 reports these estimates. The structure of Table 3 is as follows. The first three columns present the estimates based on years of education. The next three columns present the estimates based on college education. Within columns we distinguish between father's and mother's education. The first three panels present estimates for the random sample of non-adopted children. We first look at all children, and then at sons and daughters, separately. The next three panels present estimates of the same regressions using the adoptees. All regressions include an intercept and individual controls for the child's age and gender, and the father's/mother's age. These parameters are not reported. 
We begin with the estimates for non-adopted children. As expected the coefficients are strongly significantly different from zero. The order of magnitude of the estimates for years of schooling suggests that one more year of parental education - father's or mother's - is associated with one quarter of a year more education for the child, whereas parents having college education is associated with a 25 percent higher likelihood that the child has a college education. Another result, in columns 3 and 6 , is that the coefficient for either parent's education is reduced quite substantially when the other parent's education also is incorporated in the equation. Assortative mating on education lies behind this pattern.

In the next three panels we apply the adoption approach uncritically and estimate the previous intergenerational specifications on adoption data. We find that the estimated effects fall significantly, but that the impact of parental education on the education of adoptees remains statistically significant and positive. One additional year of parent's education increases child's education by one-tenth of a year. Much of the recent literature on intergenerational transmissions of education has found positive effects for father's education but no or insignificant effects of mother's education (see Behrman \& Rosenzweig 2002; Plug 2004). When we include both parents' education in the regression, the effect of father's education is higher for years of schooling but not for college education. Since both mother's and father's education have positive and significant effects on children's education, the adoption approach suggests that both parent's education contribute to the education of the next generation. 


\subsection{The effect of parents' earnings and income: baseline results}

Table 4 reports the estimates of earnings and total income. All regressions use individual controls for the child's age and gender, and the father's/mother's age. ${ }^{19}$ Table 4 is structured as Table 3, except that we do not enter both father's and family income in the same equation. The first two columns present the estimates based on earnings, and the next two columns are based on total income.

We begin with the earnings estimates that come from a random sample of non-adopted children. In the two columns we see that higher earnings of the father/family are associated with higher earnings of the child. The elasticities we find range from 0.23 for father earnings to 0.26 for family earnings. Interestingly, the association of both father's and family earnings with own-birth sons is stronger than the association for girls. When we switch the relevant income variables to total income in columns (3) and (4), results remain virtually identical. The intergenerational earnings and income estimates for fathers and sons are similar to those obtained by Björklund \& Jäntti (1997) and Björklund \& Chadwick (2003) for Sweden.

In the next panel we apply the adoption approach. Columns (1) and (2) indicate that the estimated effects using parental earnings fall by 30 to 45 percent, but that the remaining impact of parental earnings on the earnings of adoptees is still statistically significant and positive. The earnings elasticities are now being around 0.13-0.14. In columns (3) and (4) we replace earnings for total income, and see that the elasticities are

\footnotetext{
${ }^{19}$ For fathers with incomes observed in year $\mathrm{t}(1970,1975,1980,1985$ and 1990) we first regress log income on age, age squared in year $t$ and year indicators, keep the residual from such regressions. We then take the average of these residuals over the observed twenty year period. For family earnings and income, we repeat this exercise, include the earnings and total income of both fathers and mother, and run regressions including age, age squared of both parents. The estimates on the averaged residuals are the intergenerational estimates reported in the tables.
} 
slightly higher. The association of both father's and family income (but not earnings) with adopted sons is stronger than the association for adopted girls. Our estimates indicate that the earnings and income elasticities are much lower for adoptees than for own-birth children but that they are significantly positive.

As we already mentioned, these estimates as presented are based on a number of assumptions. We now turn to sensitivity tests and examine how sensitive our estimates are to changing these assumptions. In our sensitivity analyses we will exclusively focus our attention to specifications that use years of schooling and total income, and we will further ignore gender differentials.

\section{Tests of the underlying assumptions}

\subsection{Are children randomly assigned to their adoptive parents?}

To investigate whether there is evidence of non-random assignment of adoptees (selective placement) in Sweden, we begin to compare education and income characteristics of adoptive and biological parents of adoptees. Random assignment would give us zero correlations. The first panel in Table 5, however, reports correlations that range from 0.117 to 0.144 . These numbers are quite high and suggest that non-random assignment between adoptees and their adoptive parents is substantial. ${ }^{20}$

Having established that children are not randomly assigned to their adoptive parents, it is possible that our adoption estimates are plagued by selective placements. We therefore

\footnotetext{
${ }^{20}$ These correlations are not driven by age and region effects. When we regress out age, age squared and a set of region dummies, the correlations remain virtually identical. Also, note that the magnitude of the correlations is very similar to the correlations in IQ between the biological and adoptive mother/father found in one of the most well known samples of adoptees used for research purposes, the Texas Adoption Study (Brody, 1972).
} 
need to take these potential selection effects into account. In Table 5 we further present two separate tests where these selection effects are important.

In our first test we limit our sample to adoptees for whom we have outcome information on both natural and adoptive parents, and run two separate regressions on this restricted adoption sample. We first re-estimate previous models and test whether the intergenerational effects correspond to those previously reported. These estimates are presented in the second panel of Table 5. We find positive and significant effects, very close to those observed for all adoptees. The likelihood ratio tests -not reported in this paper- further reveal that none of the estimated coefficients varies across adoptees with and without information available on their birth parents.

We then estimate the intergenerational baseline models for the same sample of adoptees, but also include characteristics of biological parents as additional regressors. The underlying idea of this test is fairly simple. If the adoptees' natural and adoptive parents have something in common, and that something correlates with earnings and income, then intergenerational effects as estimated in the previous panel also capture selection effects. Because part of the treatment effect as identified by adoption now comes from the adoptees' own-birth parents, we should be able to control for it by adding the outcome measures of the adoptees' own-birth parents as additional regressors. Panel 3 in Table 5 presents these regression results. Much to our surprise, we find that the estimates of the impact of adoptive parents' characteristics on those of their children are quite insensitive to the inclusion of the birth parents' characteristics. The estimates vary between 0.046 and 0.106 for education and between 0.145 and 0.165 for income. These 
estimates are only about 10-20 percent lower for education, and 5-10 percent lower for income, compared to those reported in previous panel.

The results regarding the impact of the biological parents' outcomes on their children brought up by adoptive parents are somewhat mixed. The education effects of birth parents are positive and significant and somewhat bigger than the effects for adoptive parents. The income effects of birth parents are only statistically significant and positive when we consider the income that is generated by both birth parents. The income effects of birth fathers are small in size, and statistically insignificant. These particular income effects not only pick up that part of income that is due to selection, but also that part of income that is genetically driven.

We note the very interesting result that the sum of the schooling estimates for adopted and birth parents are very similar to the estimates for own-birth children and their biological parents (as in panel 1 of table 3 ). This indicates that the adoption per se (the break from the biological mother, the time at the nursery) has no effect on the strength of the intergenerational schooling association among parents and children. ${ }^{21}$

The second test identifies the degree of selective placement of adoptees directly and involves children who are raised by their own-birth parents in the presence of adopted siblings. We limit our sample of own birth children to children with adopted siblings for whom we have education or income information available on their biological parents. We then run regressions on this restricted sample using the outcome of the adopted siblings' birth parents as explanatory variables and as dependent variable the outcome of the adoptive parents' biological child. Any estimated effect can only come from selection. In

\footnotetext{
${ }^{21}$ Of course, the average adoptee could still (and does) do worse than the average non-adoptee, as captured by the estimated intercepts.
} 
the fourth and final panel of Table 5, we observe that these estimated income effects are very close to zero, but that the corresponding estimates for education reported are positive and significantly different from zero. It is possible that at the time these children are assigned to their new families, matching was easier on observed schooling than on unobserved long-run income.

To conclude, selective placement appears to be common practice in Sweden in the 1960s, but does not affect our results based on the adoption approach that much.

\subsection{The timing of adoptions}

So far we have ignored adoption age although such a variable seems reasonable to include in a causal model for adopted children's outcomes as adults. The reason for doing so is that most previous studies have not had access to information about adoption age and thus implicitly assume that adoption took place at birth. We now use the information about adoption age that we have from the censuses in 1965, 1970 and 1975 . We perform three separate tests of whether children are not adopted immediately at birth will impact our intergenerational estimates.

The first test is rather straightforward. We re-estimate previous models using only children who we know were adopted as babies. ${ }^{22}$ The idea is that treatment effects should then be estimated more accurately using a sample that is limited to adoptees who receive the full parental treatment. Results are reported in the first panel of Table 6 . The estimates attached to all the income variables and to mothers' education (but not fathers')

\footnotetext{
${ }^{22}$ Because the censuses were performed in November 1965, 1970 and 1975, we define babies as those children who were born on average within twelve months before a census and lived with their adoptive parents in the census.
} 
indicate that effects are indeed somewhat bigger (although in most cases not significantly different) for adoptees who are adopted as babies.

In the second test we use the full adoption sample and allow treatment effects to be different for children adopted at different ages through interaction effects. We re-run the regressions and add both adoption age and adoption age interacted with the parental outcome variables as additional regressors. A negative interaction effect would then correspond with the idea that children adopted at a later age receive only part of the treatment. The estimates reported for the parental outcome variables in panel 2 of Table 6 should be interpreted as the effects estimated to be for children adopted at birth $\left(a^{c}=0\right)$. Timing effects do not seem to be important for education. In the first three columns we find that the interaction effects are close to zero and statistically insignificant and that the estimated effects for children adopted at birth are quite similar to the reported estimates in Table 3. When we look at income instead of schooling, the interacted effects are marginally significant and negative. Now timing of adoption does seem to affect the treatment children receive. The effect of age of placement on the treatment is relatively small. Provided that timing effects are correctly specified, these estimates can still predict the intergenerational estimate. Conditional upon adoption at birth, the elasticities we find range from 0.20 for father and child income to 0.22 for family and child income. These numbers are about 15 percent smaller than those obtained using the birth sample reported in Table 4.

In the last row of Table 6 we also report the main effects of adoption age. The main and interacted affects are always jointly statistically significant. The pattern is consistent with the idea that children adopted at a younger age obtain, in the end, more education 
and income. Although one should be careful in interpreting these effects as causal, they do suggest that adoptions should take place when the child is as young as possible.

All in all, the results in this section give no compelling reason to believe that timing of adoption seriously affects the effect estimates obtained from models that neglect this variable, especially when we consider the effect of schooling.

\subsection{Are adoptees and their parents different?}

We now turn to the external validity question, namely whether we can extrapolate our adoption results to all parents and their own-birth children. Extrapolation requires a set of assumptions. In this section we test whether we can maintain these assumptions. We present three separate tests.

First, we test for differential treatment effects for adoptees and own-birth children who were reared in the same family. We compare intergenerational estimates from separate regressions for the sample of adoptees with only own-birth siblings and adoptees with only siblings who are adopted by the rearing parents. Thus, single-children families and families without adopted children are excluded. We also control for sibling size in the regressions. If the effects to be estimated are similar we would conclude that treatment effects are the same for adoptees and own birth children. Table 7 indicates that with respect to the estimated schooling effects, parents appear to have a tendency to favor their own-birth children over their adopted children. The coefficients that belong to parental schooling are slightly larger for adoptees with only adopted siblings. For the income effects, however, there are no observed differences among adoptees with and without adopted siblings. The last row report test statistics and corresponding $p$-values of tests of 
equality between estimates in both panels. In none of these estimations, we can reject equality in coefficients between the groups. We conclude there is no evidence of differential treatment effects among adoptees and own-birth children, and that the generality of our estimates is not sensitive to this potential problem.

Second, we exploit a similar idea to test whether our estimates are affected by any unobserved differences between adoptive parents and parents raising their own-birth children. We compare the estimated intergenerational relationships between biological parents and their own-birth children (as in panel 1 of Tables 3 and 4) in families with and without adopted children. Again we exclude single children families and families with only adopted children. If adoptive parents have better unobserved parental skills in ways related to the treatment, then bigger intergenerational effects will be obtained. This is not the case. Table 8 reports positive and significant estimates for own-birth children with parents that also adopt, identical to the effects observed for all other own-birth children.

Third, we test whether unobservable differences between adoptees and own-birth children affect our estimates. We do this by comparing the estimated intergenerational relationships between biological parents and their own-birth children, in families with and without a child adopted out from the family. If children who are given up for adoption are indeed different from other children, we should then observe treatment effects for this group that are more comparable to the effects found for adoptive parents and their adopted children. We don't observe this. Table 9 reports positive and significant intergenerational effects, much more similar to the effects observed for all other ownbirth children. 
In Tables 8 and 9 we tested whether adoptees and adoptive parents are different from other children and their parents, and that our effect estimates are possibly biased because of omitted variable bias. Our results indicate that they are not.

\subsection{Are intergenerational effects linear?}

The final issue we address is that the specifications we use are linear in years of schooling and log earnings. This raises a number of questions, of which two concern measurement and functional form. First, can we use years of schooling as a reasonable schooling measure in Sweden? And second, can we use linear functions to approximate intergenerational effects of schooling and income for adopted and own birth children?

In this paper we measure schooling in years and income in logarithms as it is commonly measured and used in labor economics. The use of years of schooling as a schooling measure in Sweden, however, is perhaps too simple. At the time of data collection, the Swedish school system had parallel tracks. The second, and related, question is more relevant. Because parents that adopt are more often better educated and richer parents than parents that raise their own birth children, it is possible that the different effects estimates found for adoptive and non-adoptive parents are driven by non-linear effects. In particular, we should observe smaller mobility effects for adoptive parents and their children if marginal effects fall with more schooling and/or income.

In Table 10 we test for non-linear schooling effects by replacing the years of schooling measure with a set of school level dummies. The six levels we distinguish are primary school, lower secondary education, short and long upper secondary education, and short and long tertiary education. With schooling measured in levels, we still find that better 
educated fathers and mothers get children that stay in school longer. In comparison with the years of schooling specification as discussed earlier, we find that the linear mobility representation is a pretty accurate approximation of the overall relationship, even though the returns to one extra year of upper secondary or of long college clearly pays off very well in terms of child outcomes. In columns (4) and (5) we address non-linearity by employing a linear spline function in income measured in logarithms. Defining the distribution of income on the basis of the full birth sample, cutpoints of the spline function are placed at the 25 th, 50 th, and 75 th percentile of the distribution, thus allowing income to exert varying strengths in the different income quartiles. For all income measures, we find that slopes are always statistically significantly positive. The splines further indicate that the intergenerational dependency is smallest in the first quartile and highest in third quartile. The fluctuations across quartiles are rather difficult to reconcile with a linear specification. But since the estimated mobility effects in the fourth quartile almost always exceed average effects, we tentatively conclude that the difference in estimated effects observed for adoptive and own-birth parents cannot be driven by non-linearities. ${ }^{23}$

\section{Discussion and conclusions}

We have scrutinized the adoption data approach to estimating effects of parental resources (education and income/earnings) on the same outcomes for offspring. Thanks to a large data set drawn from Swedish administrative records, with detailed information on biological background and adoption history of adoptees, we could examine the basic

\footnotetext{
${ }^{23}$ Plug and Vijverberg (2004) use splining to test for the presence of credit constraints when parents finance their adopted children's education. Their results, although imprecisely estimated, suggest that US parents are indeed credit constrained.
} 
assumptions, which the adoption approach strongly relies upon. We discuss what we think are the three most important assumptions.

The first assumption is that of random assignment of adopted children to adoptive families, the violation of which would cause a correlation in genetic inheritance between adopted children and their adoptive parents. Our data show that even though adoptees in Sweden are not always randomly assigned to their adoptive parents, the intergenerational effect estimates are not tainted by selective placements. The second assumption is that parents should not treat their adopted and own-birth children differently with respect to the time and money they invest in them. Our data provide no evidence that there are such differences in upbringing. The third assumption tackles the problem that adoptees and their parents are different from other children and their parents. Our data indeed indicates that our intergenerational estimates are not biased because of omitted variables that are typical to either adoptees or adoptive parents.

All in all, we are inclined to conclude that the adoption approach has survived our scrutiny quite well. A skeptic could, of course, argue that some of our tests - maybe in particular the ones regarding differential treatment - have low power. We are also aware that our results do not necessarily carry over to adoption data for other countries and to other periods of time since adoption institutions are country-specific and change over time, and that an adoption approach, due to unobserved parental skills, still fails in finding the causal intergenerational effect even when inherited traits are accounted for. Nonetheless, we have shown that an adoption approach can indeed be credited for reducing the bias in intergenerational effect estimates substantially. 
While we find that the regression based results hold up very well to relaxation of the assumptions, this does not necessarily imply that this is also the case if variance decomposition techniques are applied on adoptions data to partition the variance of outcomes into genetics and environment. Such work on the data used in this paper is currently underway.

We conclude the paper by discussing our substantive results about causal intergenerational effects and comparing them with those in some recent studies on the intergenerational mobility of schooling and income. To date there are six such studies that focus on years of schooling, use three different approaches, and do make a distinction between causation and association: one identical twins study, two adoption studies and three instrumental-variable (IV) studies.

With monozygotic twin mothers from Minnesota, identical in their inborn abilities but different in their amounts of schooling, Behrman and Rosenzweig (2002) obtain identification by taking the difference between the twin mothers' children. They find that the mother's schooling has little if any impact on the schooling of her child. However, once they look at monozygothic twin fathers and difference out all the genetic abilities that influence their children's schooling, the influence of father's schooling remains positive and statistically significant.

Sacerdote (2000) and Plug (2004) also consider the effects of unobserved inherited abilities on the child's schooling, but, instead of twinning, obtain identification from adopted children. With relatively small samples they find positive and statistically significant schooling effects when mother's and father's schooling are included as separate regressors. Consistent with the previous twin study, they find that the effect of the mother's 
schooling is most sensitive to the inclusion of her partner's schooling. Controlling for inherited abilities and assortative mating, Plug (2004) finds that the association between mother's (but not father's) and child schooling appears small and statistically insignificant while in Sacerdote's study the partial effect of maternal schooling is positive and statistically significant. ${ }^{24}$

Three recent IV studies exploit reforms in the compulsory schooling legislation to identify the effect of parent's schooling on their children's. Oreopoulos, Page and Stevens (2003) use U.S. reforms, which occurred in different states at different times and find that when the mother's and father's schooling are included as separate regressors, the influence of the mother's and father's schooling are equally important. When mother's and father's schooling are included simultaneously to allow for assortative mating effects, the estimates are no longer significantly different from zero or from each other. Because of the imprecision of their estimates, however, it is impossible to say anything about the mother's and father's relative importance in the transmission process. Black, Deveroux and Salvanes (2004) also use changes in compulsory schooling laws introduced in different Norwegian municipalities at different times during the sixties and early seventies. They find no effect of father's schooling and a small but positive effect of mother's schooling (which is primarily driven by the mother-son relationship). In a similar fashion Chevalier (2004) uses a change in the compulsory schooling law in Britain in 1957. He finds a large positive effect of mother's education on her child's education but no significant effect of paternal education. However, his study suffers from the fact that the legislation was implemented

\footnotetext{
${ }^{24}$ Sacerdote uses 170 adoptees that come from the National Longitudinal Survey of Youth while Plug uses 610 adoptees that come from the Wisconsin Longitudinal Survey. Sacerdote's study does not report results where the mother's and father's schooling are included simultaneously. We are grateful to Bruce Sacerdote for running the latter specification on request.
} 
nationwide; as a result, there is no cross-sectional variation in the British compulsory schooling law.

Our results are most comparable to those obtained in previous adoption studies. The estimated impacts of both mother's and father's schooling on the adopted child's schooling are positive, statistically significant, and equally important. But when we include both parents' schooling in the regression, the partial effect of father's schooling is higher. But since both mother's and father's schooling remains to have positive and significant effects on their children's schooling, we conclude that both parent's schooling contribute to the schooling of the next generation.

Where all these differences come from, we do not know. Perhaps, differences are due to the locality of the treatment. Adoptive parents are, on average, better educated whereas the parents that are affected by the instruments are always less educated. Or perhaps it is the case that the observed differences are country specific. Possible answers will indeed be fascinating but are not addressed in this paper.

There are even fewer studies available that attempt to identify the causal effects of parental earnings and income in earnings and income mobility studies: one adoption study and two IV-studies. To begin with the latter, Mayer's (1997) and Shea's (2000) approaches require strong identifying assumptions, which are not always convincing. Nonetheless, their results are interesting. They find that unanticipated changes in parental long-run earnings and income have at most a negligible effect on the earnings and income of the child.

Again, Sacerdote (2000) examines adoptees and own birth children to disentangle the relative contribution of nature and nurture in the intergenerational mobility of income. With 
a sample of own-birth children and their parents, he finds elasticities that are positive and statistically significant. With adoptees, the elasticities are still positive but imprecisely estimated. The adoption estimates are no longer significantly different from zero, nor different from the own-birth estimates for that matter. Perhaps, because his sample is small and family income is measured for only one year.

Here our study clearly offers an important contribution. With a much larger sample of adoptees, and measuring the earnings and income of parents over a period of 20 years, we come to the conclusion that the child's earnings and income are indeed affected by parent's earnings and income, and these effects are precisely estimated. 


\section{References:}

Aghion P \& P Howitt (1998), Endogenous Growth Theory, Cambridge MA, MIT Press.

Allmänna barnhuset (1955), Adoption. Handbook for social workers and authorities responsible for adoption issues.

Allmänna barnhuset (1969) Adoption. Handbook for social workers and authorities responsible for adoption issues.

Asklund Lis (1960) "Som vårt eget... En bok för adoptivföräldrar". (As our own...A book for adoptive parents). Allmänna barnhuset 1960.

Behrman, Jere R., Paul Taubman \& Terence Wales (1977), "Controlling for and Measuring the Effects of Genetics and Family Environment in Equations for Schooling and Labor Market Success." In Kinometrics: Determinants of Socioeconomic Success within and between Families, edited by Paul Taubman. Amsterdam: North-Holland.

Behrman Jere and Mark Rosenzweig (2002) "Does Increasing Women's Schooling Raise the Schooling of the Next Generation?", American Economic Review 92 (1), 323-334.

Benabou Ronald (1996) "Heterogeneity, Stratification and Growth: Macroeconomic Implications of Community Stratification and School Finance", American Economic Review (86): 584-609.

Björklund Anders and Laura Chadwick (2003), "Intergenerational income mobility in permanent and separated families", Economics Letters 80: 239-246.

Björklund Anders \& Markus Jäntti (1997), "Intergenerational Income Mobility in Sweden Compared to the United States", American Economic Review, 87 (5): 1009-1018.

Björklund Anders, Markus Jäntti \& Gary Solon (2004, forthcoming), Influences of Nature and Nurture on Earnings Variation: A Report on a Study of Sibling Types in Sweden, in Bowles, Gintis \& Osborne (eds.) Unequal chances: Family Background and Economic Success, New York: Russel Sage Foundation.

Björklund, Anders \& Katarina Richardson (2001), "The Educational Attainment of Adopted Children Born Abroad”, mimeo.

Black, Sandra, Paul J. Devereux \& Kjell G. Salvanes (2003), "Why the Apple Doesn't Fall Far: Understanding Intergenerational Transmission of Human Capital”, NBER WP 10066.

Brody, Nathan (1992), Intelligence, $2^{\text {nd }}$ edition. Academic Press.

Case Anne, I-Fen Lin \& Sara McLanahan (2000), "How Hungry is the Selfish Gene?" Economic Journal 110 (466), pp. 781-804. 
Chevalier Arnaud (2004), "Parental Education and Child's Education: A Natural Experiment”, IZA WP no. 1153.

Das Mitali \& Tanja Sjogren (2002), "The inter-generational link in income mobility: evidence from adoptions", Economics Letters 75: 55-60.

Dearden Lorraine, Stephen Machin \& Howard Reed (1997), Intergenerational Mobility in Britain, Economic Journal 110: 47-64.

DeFries, J. C., and Robert Plomin (1978), "Behavioral Genetics," Annual Review of Psychology 1978 (29), 473-515.

Goldberger, Arthur S. (1979), "Heritability”, Economica 46(184): 327-47.

Jencks Christoffer (1972), Inequality., Basic Books, Inc.

Kamin, Leon J., and Arthur S. Goldberger (2002), “Twin Studies in Behavioral Research: A Skeptical View.” Theoretical Population Biology 61(1): 83-95.

Kungl. Socialstyrelsen (1959). “Råd och anvisningar i socialvårdsfrågor”, nr. 117.

Kungl. Socialstyrelsen (1968). "Råd och anvisningar i socialvårdsfrågor”, nr. 209.

Mayer Susan (1997), What Money Can't Buy: Family Income and Children's Life Chances, Cambridge MA, Harvard University Press.

Nordlöf Barbro (2001), Svenska adoptioner i Stockholm 1918-1973 (Swedish adoptions in Stockholm 1918-1973). FOU-rapport 2001:8 Socialtjänstförvaltningen, Stockholm Stad.

Oreopoulus Philip, Marianne E. Page \& Anne Huff Stevens (2003), "Does Human Capital Transfer from Parent to Child? The Intergenerational Effects of Compulsory Schooling", NBER WP 10164.

Plug, Erik (2004), “Estimating the Effect of Mother's Schooling on Children's Schooling Using a Sample of Adoptees", American Economic Review 94(1): 358-368.

Plug Erik \& Wim Vijverberg (2004), "Does Family Income Matter For Schooling Outcomes? Using Adoption As a Natural Experiment", mimeo.

Plug Erik \& Wim Vijverberg (2003), Schooling, Family Background, and Adoption: Is It Nature or Is It Nurture?, Journal of Political Economy 111(3): 611-641.

Sacerdote Bruce (2000), "The Nature and Nurture of Economic Outcomes”, NBER WP no. 7949. 
Sacerdote Bruce (2002), "The Nature and Nurture of Economic Outcomes", American Economic Review Papers and Proceedings 92 (May 2002): 344-348.

Scarr, Sandra, and Richard Weinberg (1978), "The Influence of Family Background on Intellectual Attainment," American Sociological Review 58, 674-692.

Shea John (2000), “Does parents' money matter?”, Journal of Public Economics 77: 155184.

Solon Gary (1999), Intergenerational Mobility in the Labor Market. In: Ashenfelter O and D Card (eds.), Handbook of Labor Economics, vol. 3, Elsevier, Amsterdam.

Taubman, Paul (1976). "The Determinants of Earnings: Genetics, Family, and Other Environments; A Study of White Male Twins." American Economic Review 66(5): 858-70. 
Table 1. Number of adoptees by birth cohort and selection rule

\begin{tabular}{lcclc}
\hline Cohort & I. All adoptees & $\begin{array}{l}\text { II. Exclude those who were } \\
\text { adopted after age 7.5, died at } \\
\text { age }<27, \text { those with too young } \\
\text { adoptive parent }(<25) \text {, those } \\
\text { with too old adoptive parent } \\
\text { (mother }>47 \text { or father }>66)\end{array}$ & $\begin{array}{l}\text { III. Exclude } \\
\text { those with } \\
\text { missing } \\
\text { education data }\end{array}$ & $\begin{array}{l}\text { IV. Exclude } \\
\text { those with } \\
\text { missing } \\
\text { income data }\end{array}$ \\
\hline 1962 & 1106 & 1047 & 1004 & 939 \\
1963 & 1125 & 1049 & 1016 & 962 \\
1964 & 1150 & 1055 & 1024 & 964 \\
1965 & 1015 & 879 & 866 & 804 \\
1966 & 896 & 838 & 820 & 754 \\
1967 & 730 & 682 & 669 & 628 \\
1968 & 551 & 515 & 512 & 484 \\
1969 & 423 & 386 & 380 & 360 \\
1970 & 430 & 382 & 379 & - \\
1971 & 362 & 342 & 277 & - \\
1972 & 294 & 279 & 213 & - \\
1973 & 227 & 214 & 7498 & 5895 \\
\hline Total & 8309 & 7668 & & - \\
\hline
\end{tabular}

We computed adoption age by taking the midpoint of the difference between the date of the first census where the child is living with the adopted parents and the birth date. Since the distribution of age of adoption is right skewed, this will overstate the adoption age for most children. 
Table 2. Means and standard deviations (in italics) of selected variables for adopted and non-adopted children, and birth and adoptive parents.

\begin{tabular}{|c|c|c|c|c|}
\hline \multirow[b]{3}{*}{ Years of schooling } & \multicolumn{2}{|c|}{ Non-adopted children } & \multicolumn{2}{|c|}{ Adopted children } \\
\hline & \multicolumn{4}{|c|}{ Children } \\
\hline & 12.039 & 2.045 & 11.732 & 1.912 \\
\hline College education & 0.130 & 0.337 & 0.089 & 0.284 \\
\hline Log earnings in 1999 & 7.511 & 0.680 & 7.405 & 0.723 \\
\hline Log income in 1999 & 7.599 & 0.567 & 7.525 & 0.581 \\
\hline Female & 0.487 & 0.499 & 0.474 & 0.499 \\
\hline Age in 1999 & 33.489 & 3.020 & 33.497 & 3.094 \\
\hline \multirow[t]{2}{*}{ Adoption age } & & & 1.801 & 1.189 \\
\hline & \multicolumn{4}{|c|}{ Birth parents } \\
\hline Years of schooling, father & 9.772 & 3.113 & 8.999 & 2.499 \\
\hline Years of schooling, mother & 9.870 & 2.829 & 9.299 & 2.444 \\
\hline College education, father & 0.099 & 0.299 & 0.032 & 0.177 \\
\hline College education, mother & 0.080 & 0.272 & 0.036 & 0.186 \\
\hline $\begin{array}{l}\text { Average log earnings 1970-90, } \\
\text { father }\end{array}$ & 7.649 & 0.438 & 7.340 & 0.527 \\
\hline $\begin{array}{l}\text { Average log earnings } 1970-90 \text {, } \\
\text { family }\end{array}$ & 7.944 & 0.438 & 7.405 & 0.615 \\
\hline $\begin{array}{l}\text { Average log income 1970-90, } \\
\text { father }\end{array}$ & 7.666 & 0.429 & 7.358 & 0.477 \\
\hline $\begin{array}{l}\text { Average log income 1970-90, } \\
\text { family }\end{array}$ & 7.982 & 0.409 & 7.452 & 0.569 \\
\hline Age at child's birth, father & 29.801 & 6.511 & 27.545 & 7.833 \\
\hline Age at child's birth, mother & 26.640 & 5.619 & 23.483 & 6.052 \\
\hline Teenage mother & 0.103 & 0.304 & 0.293 & 0.455 \\
\hline \multirow[t]{2}{*}{ Teenage father } & 0.025 & 0.156 & 0.068 & 0.253 \\
\hline & \multicolumn{4}{|c|}{ Adoptive parents } \\
\hline Years of schooling, father & & & 10.410 & 3.364 \\
\hline Years of schooling, mother & & & 10.000 & 3.036 \\
\hline College education, father & & & 0.150 & 0.358 \\
\hline College education, mother & & & 0.109 & 0.312 \\
\hline $\begin{array}{l}\text { Average log earnings 1970-90, } \\
\text { father }\end{array}$ & & & 7.785 & 0.456 \\
\hline $\begin{array}{l}\text { Average log earnings } 1970-90 \text {, } \\
\text { family }\end{array}$ & & & 8.005 & 0.452 \\
\hline $\begin{array}{l}\text { Average log income 1970-90, } \\
\text { father }\end{array}$ & & & 7.814 & 0.434 \\
\hline $\begin{array}{l}\text { Average log income 1970-90, } \\
\text { family }\end{array}$ & & & 8.052 & 0.429 \\
\hline Age at child's birth, father & & & 35.044 & 5.330 \\
\hline Age at child's birth, mother & & & 32.320 & 4.808 \\
\hline Number of observations & & & & \\
\hline
\end{tabular}


Table 3. EFFECTS OF PARENTS' SCHOOLING ON CHILDREN'S SCHOOLING Years of schooling

College education
(1)
(2)
(3)
(4)
(5)
(6)

Birth father

Own-birth children

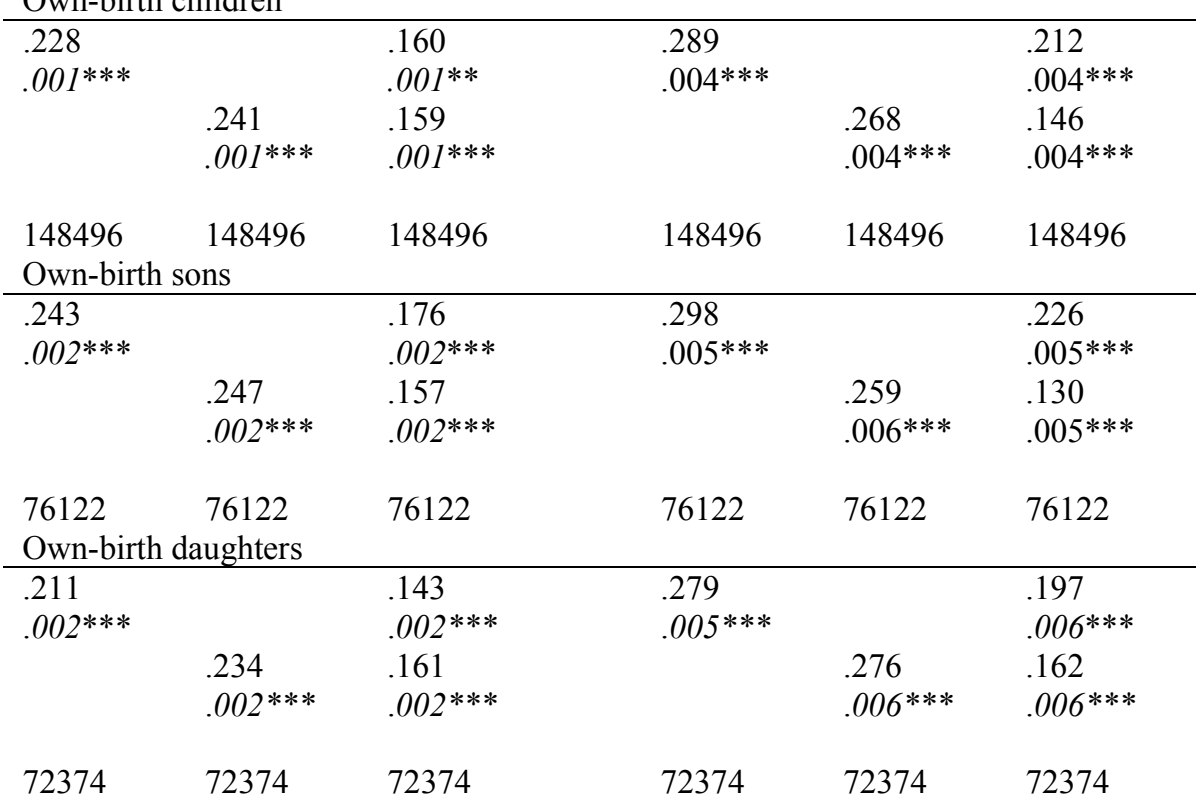

Number of obs

Adoptees

Adoptive father

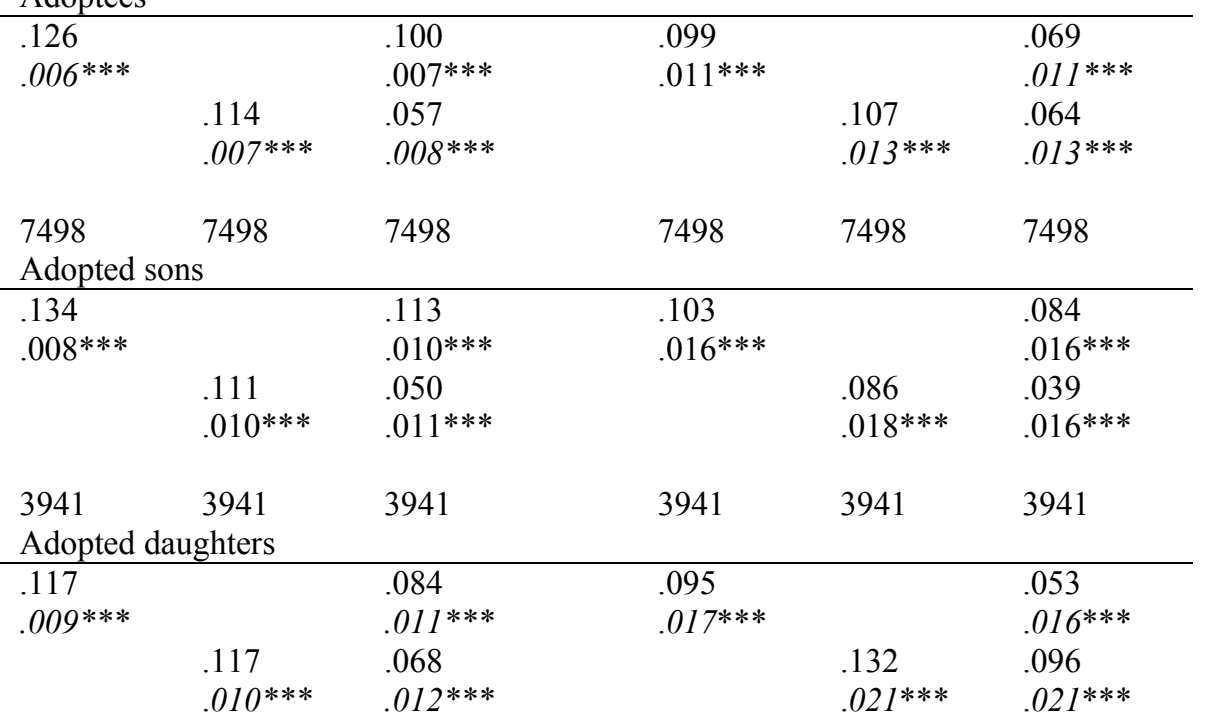

Number of obs

Adoptive father

Adoptive mother

Number of obs

Adoptive father Adopted daughters

Adoptive mother

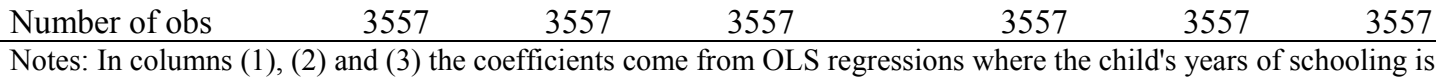

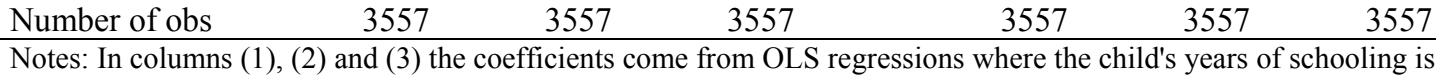

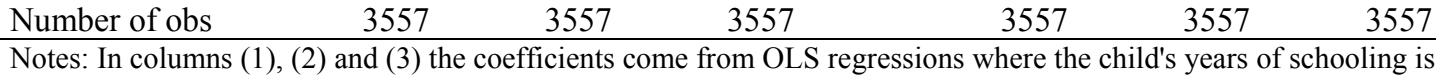

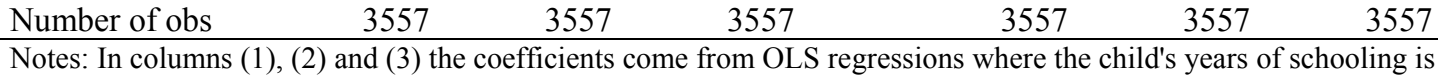
regressed on the parent's years of schooling. In columns (4), (5) and (6) the coefficients which represent partial derivatives come from probit regressions where the child's university graduation is regressed on the parent's university graduation. In each panel, each column represents a separate regression. All panels represent regressions on separate birth and adoption samples. All specifications include a constant and controls for child's, mother's and father's age. In panels (1) and (4) we also include a control for gender. These parameters are not reported. Standard errors are shown in italics, $*$ indicates significance at $10 \%$ level,$* *$ indicates significance at $5 \%$ level, and $* * *$ significant at $1 \%$ level. 
Table 4. EFFECTS OF FATHER AND FAMILY INCOME ON CHILDREN'S INCOME Earnings

Total income
(1)
(2)
(3)
(4)

Birth father

Own-birth children

$\begin{array}{llll}.232 & & .230 \\ .004 * * * & & .003^{* * *} & \\ & .265 & & .264 \\ & .004^{* * *} & & .003^{* * *} \\ & & & \\ 115045 & 115045 & 121981 & 121981\end{array}$

Birth father

Own-birth sons

Birth family

$.005 * * *$

.276

Birth family

.287

\section{.287}

$.005^{* * *}$

$.006^{* * *}$

.304

$59303 \quad 59303$

62531

62531

Number of obs

Birth father

Own-birth daughters

$.203 \quad .182$

Birth family

$.006^{* * *}$

$.004 * * *$

.242

.222

$.006 * * *$

$.005 * * *$

Number of obs

$55742 \quad 55742$

59450

59450

Adoptive father

Adoptees

$\begin{array}{llll}.128 & & .162 & \\ .020^{* * *} & & .016^{* * *} & \\ & .143 & & .154 \\ & .021^{* * *} & & .017^{* * *}\end{array}$

Number of obs

5431

5431

5895

5895

Adoptive father

\section{Adopted sons}

$$
.134
$$$$
.190
$$

$.029 * * *$

$.024 * * *$

\section{.143}

$.030 * * *$

.173

$.025^{* * *}$

$2885 \quad 2885 \quad 3108 \quad 3108$

Adopted daughters

Adoptive father

Adoptive family

$$
\begin{aligned}
& .121 \\
& .029 * * *
\end{aligned}
$$

\section{.144}

$021 * * *$

.134

$.024 * * *$

Number of obs

2547

2547

2787

2787

In columns (1) and (2) the coefficients come from OLS regressions where child's earnings is regressed on earnings of the father and the earnings of both the mother and the father. The dependent variable is the log of the child's annual earnings in 1999. The independent variable is the average of log earnings taken over a 20 year period running from 1970 to 1990. In columns (3) and (4) the annual earnings of child, mother and father are replaced with annual total income.. In a panel, each column represents a separate regression. All panels represent regressions on separate birth and adoption samples. All specifications include a constant and controls for child's, mother's and father's age. In panels (1) and (4) also control for child's gender. These parameters are not reported. Standard errors are shown in italics, * indicates significance at $10 \%$ level, ${ }^{* *}$ indicates significance at $5 \%$ level, and $* * *$ significant at $1 \%$ level 
Table 5. WHAT HAPPENS IF NOT ALL ADOPTEES ARE RANDOMLY ASSIGNED? Years of schooling Total income
(1)
(2)
(3)
(4)
(5)

Corr (birth father, adoptive father)

Correlations for our sample of adoptees $.006^{* * *}$

.117

$.005^{* * *}$

Corr (birth mother/ family, adoptive mother/family) Number of obs 3527

.144

$.006^{* * *}$

3527

3527

2972

$.006^{* * *}$

3050

Adoptees for which we have information on both birth parents

\begin{tabular}{|c|c|c|c|c|}
\hline \multirow{3}{*}{$\begin{array}{l}.117 \\
.009^{* * *}\end{array}$} & & .090 & \multicolumn{2}{|l|}{.173} \\
\hline & & & & \\
\hline & $\begin{array}{l}.109 \\
010^{* * * *}\end{array}$ & .059 & & $\begin{array}{l}.158 \\
.023^{* * * *}\end{array}$ \\
\hline & & & & \\
\hline \multicolumn{5}{|c|}{ Adoptees for which we include information of birth parents } \\
\hline .106 & & .072 & .165 & \\
\hline $.009 * * *$ & & $.010^{* * *}$ & $.026^{* * *}$ & \\
\hline & .092 & .046 & & .145 \\
\hline & $.010^{* * *}$ & $.011 * * *$ & & $.029 * * *$ \\
\hline 108 & & .083 & .035 & \\
\hline $.012 * * *$ & & $.012 * * *$ & $.025 * * *$ & \\
\hline & .145 & 115 & & .071 \\
\hline & $.013^{* * *}$ & $.013^{* * *}$ & & $.025^{* * *}$ \\
\hline 3527 & 3527 & 3527 & 2972 & 3050 \\
\hline
\end{tabular}

Own birth children for which we include information of adopted sibling's birth parents

$\begin{array}{lll}.050 & .034 & .005 \\ .025^{* *} & .025 & .039\end{array}$

birth father

$\begin{array}{ll}.088 & .080 \\ .026^{* * *} & .026^{* * *}\end{array}$

1242

1242

1242

699
732

In panel (1) correlations between adoptees' birth and adoptive parents are reported. In columns (4) and (5) the correlations on Log annual income. In remaining panels intergenerational mobility estimates are reported. In columns (1), (2) and (3) the coefficients come from OLS regressions where the child's years of schooling is regressed on the parent's years of schooling. In columns (4) and (5) the coefficients come from OLS regressions where the child's total income is regressed on the total income of the father and the total income of the family. The dependent variable is the $\log$ of the child's annual total income obtained in 1999. The independent variable is the average of log total income taken over a 20 year period running from 1970 to 1990 . By mother/family we mean that the years of schooling of the mother is used in the estimations in columns 1-3 and that the total income of the family is used in columns 4-5. In a panel, each column represents a separate regression. In panels (2) and (3) estimates come from a sample of adoptees for which information on both birth and adoptive parents is available. In panel (2) all specifications include a constant and controls for the child's age and gender, and adoptive mother's and father's age. In panel (3) we also include controls for the adoptees' birth mother's and father's age. In panel (4) estimates come from a sample of own birth children with adopted siblings for which information on both birth parents is available. The specifications include a constant and controls for the child's age and gender, and birth mother's and father's age.

Standard errors are shown in italics, * indicates significance at $10 \%$ level ,** indicates significance at $5 \%$ level, and $* * *$ significant at $1 \%$ level. 
Table 6. WHAT HAPPENS IF NOT ALL ADOPTEES ARE ADOPTED AS BABIES? Years of schooling Total income

(3)

(4)

(5)

\begin{tabular}{|c|c|c|c|c|}
\hline .143 & & .118 & .139 & \\
\hline $.013 * * *$ & & $.015^{* * *}$ & $.033 * * *$ & \\
\hline & .121 & .056 & & .156 \\
\hline & $.014 * * *$ & $.016^{* * *}$ & & $.035 * * *$ \\
\hline 1725 & 1725 & 1725 & 1496 & 1496 \\
\hline Model in & racted wit & doption as & & \\
\hline .135 & & .108 & .198 & \\
\hline $.011 * * *$ & & $.013 * * *$ & $.029 * * *$ & \\
\hline & .119 & .058 & & .219 \\
\hline & $.012 * * *$ & $.014 * * *$ & & $.032 * * *$ \\
\hline-.015 & -.040 & -.013 & -.018 & -.019 \\
\hline .059 & .062 & .069 & $.006 * * *$ & $.006^{* * *}$ \\
\hline-.005 & & -.005 & -.023 & \\
\hline .005 & & .006 & $.014^{*}$ & \\
\hline & -.004 & -.001 & & -.040 \\
\hline & .006 & .006 & & $.006^{* * *}$ \\
\hline 7498 & 7498 & 7498 & 5895 & 5895 \\
\hline
\end{tabular}

Adoptive father

Adoptive

mother/family

Number of obs

Adoptive father

Adoptive

mother/family

Adoption age (a)

Adoptive father

interacted with $a$

Adoptive

mother/family

interacted with $a$

Number of obs

5895

In columns (1), (2) and (3) the coefficients come from OLS regressions where the child's years of schooling is regressed on the parent's years of schooling. In columns (4) and (5) the coefficients come from OLS regressions where the child's total income is regressed on the total income of the father and the total income of the family. The dependent variable is the log of the child's annual total income obtained in 1999. The independent variable is the average of log total income taken over a 20 year period running from 1970 to 1990. By mother/family we mean that the years of schooling of the mother is used in the estimations in columns 1-3 and that the total income of the family is used in columns 4-5. Standard errors are shown in italics, * indicates significance at $10 \%$ level , ${ }^{* *}$ indicates significance at $5 \%$ level, and ${ }^{* * *}$ significant at $1 \%$ level.

In a panel, each column represents a separate regression. In panel (1) estimates come from a restricted sample of adoptees who are, on average, adopted within 12 months of birth. In panel (2) estimates come from the full adoption sample with adoption age and adoption age interacted with the parent's schooling/total income included as additional regressors. All specifications further include a constant and controls for the child's age and gender, and adoptive mother's and father's age. These parameters are not reported.

Standard errors are shown in italics, * indicates significance at $10 \%$ level,$* *$ indicates significance at $5 \%$ level, and $* * *$ significant at $1 \%$ level. 
Table 7. WHAT HAPPENS IF PARENTS TREAT ADOPTEES DIFFERENT THAN THEY TREAT OWN-BIRTH CHILDREN?

Years of schooling

$\underline{\text { Total income }}$

(1)

(2)

(3)

(4)

(5)

Adoptive father

Adoptees with own-birth siblings, but without adopted siblings

$\begin{array}{lll}.113 & .102 & .113 \\ .016^{* * *} & .019^{* * *} & .049^{* *}\end{array}$

Adoptive

$.088 \quad .023$

.097

mother/family

$.019 * * * \quad .023$

$.051 *$

Number of obs

1036

1036

1036

696

696

Adoptive father

Adoptees with adopted siblings, but without own-birth siblings

$\begin{array}{lll}.162 & .140 & .094 \\ .029^{* * *} & .036^{* *} & .083\end{array}$

Adoptive

$.136 \quad .042$

.081

mother/family

$.035^{* *}$

.042

.087

Number of obs

336

336

336

265

265

Likelihood ratio test

$\begin{array}{lll}2.00 & 1.46 & 1.04 \\ .157 & .227 & .353\end{array}$

1.04
353

.04

.03

In columns (1), (2) and (3), the coefficients come from OLS regressions where the child's years of schooling is regressed on the parent's years of schooling. In columns (4) and (5) the coefficients come from OLS regressions where the child's total income is regressed on the total income of the father and the total income of the family. The dependent variable is the log of the child's annual total income obtained in 1999. The independent variable is the average of log total income taken over a 20 year period running from 1970 to 1990. In panel (1) estimates come from a restricted sample of adoptees with only siblings present that are the adoptive parents' own offspring. In panel (2) estimates come from a restricted sample of adoptees with only siblings present that are adopted as well. All specifications include a constant and controls for the child's age and gender, and adoptive mother's and father's age, and family size. These parameters are not reported. By mother/family we mean that years of schooling of the mother is used in the estimations in columns 1-3 and that total family income is used in columns 4-5. Models in panels (1) and (2) are estimated jointly using both adoption samples. All coefficients vary by sibling status. The likelihood ratio tests indicate whether the effect estimates vary across the subsamples of adoptees (panel (1) versus panel (2)). Insignificant test statistics, reported with corresponding p-values, suggest the absence of structural differences in the parental schooling/total income estimates.

Standard errors are shown in italics, $*$ indicates significance at $10 \%$ level,${ }^{* *}$ indicates significance at $5 \%$ level, and $* * *$ significant at $1 \%$ level. 
Table 8. WHAT HAPPENS IF ADOPTEES' SOCIAL OR BIOLOGICAL PARENTS ARE DIFFERENT FROM OTHER PARENTS?

Years of schooling

$\underline{\text { Total Income }}$

(1)

(2)

(3)

(4)

(5)

Birth father

Own-birth children with own-birth siblings, but without adopted siblings

$\begin{array}{lll}.231 & .161 & .243 \\ .001^{* * *} & .002^{* * *} & .004^{* * *}\end{array}$

Birth mother/family

.244

.157

.274

Number of obs

$002 * * *$

$.002 * * *$

$004 * * *$

102456

102456

102456

84947

84947

Own-birth children with adopted siblings, but without own-birth siblings

Adoptive father

$\begin{array}{lll}.203 & .121 & .223 \\ .023^{* * *} & .026^{* * *} & .061^{* * *}\end{array}$

Adoptive

.244

$.025 * * *$

.173

$.029 * * *$

630

630

630

326

Likelihood ratio test

1.55
213

0.00

.979

1.27

.282

.09

.761

.26

.610

In columns (1), (2) and (3) the coefficients come from OLS regressions where child's years of schooling is regressed on parent's years of schooling. In columns (4) and (5) the coefficients come from OLS regressions where the child's total income is regressed on the total income of the father and the total income of the family. The dependent variable is the log of the child's annual total income obtained in 1999. The independent variable is the average of log total income taken over a 20 year period running from 1970 to 1990.. By mother/family we mean that the years of schooling of the mother is used in the estimations in columns 1-3 and that the total income of the family is used in columns 4-5. In panel (1) estimates come from a restricted sample of own birth children with only siblings that are adopted. In panel (2) estimates come from a restricted sample of own birth children with only full birth siblings present. All specifications include a constant and controls for the child's age and gender, and adoptive mother's and father's age, and family size. These parameters are not reported. Models in panels (1) and (2) are estimated jointly using both birth samples. All coefficients vary by sibling status. The likelihood ratio tests indicate whether the effect estimates vary across the subsamples of birth children (panel (1) versus panel (2)). Insignificant test statistics, reported with corresponding p-values, suggest the absence of structural differences in the parental schooling/total income estimates.

Standard errors are shown in italics, * indicates significance at $10 \%$ level, ${ }^{*}$ indicates significance at $5 \%$ level, and *** significant at $1 \%$ level 
Table 9. WHAT HAPPENS IF ADOPTEES ARE DIFFERENT FROM OTHER CHILDREN?

Years of schooling

(1)

(2)

(3)

(4)
Total income

(5)

Birth father

$\begin{array}{lcr}\text { Own-birth children without siblings adopted o } \\ .227 & .160 & .230\end{array}$

$.001^{* * *}$

$.002^{* * *}$

$.003 * * *$

Birth mother/family

Number of obs

148290
Own-birth
$.207^{\text {a }}$
$.048^{* * *}$

.241

$001^{* *}$

148290

$.001^{* * *}$

148290
.264

$004 * * *$

115205

Birth father

.265

Birth mother/family

Number of obs

206

$$
.053^{*}
$$

206

.212

$.055^{* * *}$

206

115205

Likelihood ratio test $\quad .14$

.707

.15

.694

.34

.709

.145

$.049^{* * *}$

.258

$.098 * * *$

In columns (1), (2) and (3) the coefficients come from OLS regressions where child's years of schooling is regressed on parent's years of schooling. In columns (4) and (5) the coefficients come from OLS regressions where child's total income is regressed on total income of the father and total income of the family. The dependent variable is the log of the child's annual total income obtained in 1999. The independent variable is the average of log total income taken over a 20 year period running from 1970 to 1990 . Standard errors are shown in italics, * indicates significance at $10 \%$ level, ${ }^{* *}$ indicates significance at $5 \%$ level, and $* * *$ significant at $1 \%$ level. By mother/family we mean that the years of schooling of the mother is used in the estimations in columns 1-3 and that the total income of the family is used in columns 4-5. In panel (2) estimates come from a restricted sample of own birth children with full siblings that are adopted out of their birth family. In panel (1) estimates come from the remaining sample of own birth children. All specifications include a constant and controls for the child's age and gender, and birth mother's and father's age. These parameters are not reported.

Models in panels (1) and (2) are estimated jointly using both birth samples. All coefficients vary by sibling status. The likelihood ratio tests indicate whether the effect estimates vary across the subsamples of birth children (panel (1) versus panel (2)). Insignificant test statistics, reported with corresponding p-values, suggest the absence of structural differences in the parental schooling/total income estimates. 
Table 10. NON LINEAR EFFECTS OF PARENT'S SCHOOLING AND TOTAL INCOME ON CHILDREN'S SCHOOLING AND TOTAL INCOME

\section{Own-birth children Years of schooling}

$$
\text { (1) }
$$

Birth father

\begin{tabular}{ll}
\hline Compulsory lower & 0.477 \\
secondary & $0.019^{* * *}$ \\
Lower secondary & 0.459 \\
& $0.015^{* * *}$ \\
Upper secondary & 1.074 \\
& $0.014^{* * *}$ \\
Shorter college/ & 1.347 \\
university & $0.020^{* * *}$ \\
Longer college/ & 2.312 \\
university & $0.017^{* * *}$
\end{tabular}

Birth mother

Compulsory lower secondary

Lower secondary

Upper secondary

Shorter college/

university

Longer college/

university

Number of obs

$\begin{array}{ll} & 0.614 \\ & 0.015^{* * *} \\ & 0.629 \\ & 0.012^{* * *} \\ & 1.318 \\ & 0.024^{* * *} \\ & 1.663 \\ & 0.018^{* * *} \\ & 2.307 \\ & 0.019^{* * *} \\ 148496 & 148496\end{array}$

Birth family

$1^{\text {st }}$ quartile

$2^{\text {nd }}$ quartile

$3^{\text {rd }}$ quartile

$4^{\text {th }}$ quartile

Total income

(3)

(4)
0.116
$0.007^{* * *}$
0.294
$0.024^{* * *}$
0.377
$0.022 * * *$
0.283
$0.013^{* * *}$

In columns (1) and (2) the coefficients come from OLS regressions where child's years of schooling is regressed on parent's schooling measured in levels. The reference category is primary education. In columns (3) and (4) the coefficients come from OLS regressions where child's total income is regressed on a linear spline function of total income of the father and total income of the family. The cutpoints of the spline function are placed at the 25th, 50th and 75th percentile of the two different total income distributions. All estimates come from the sample of own-birth children. All specifications include a constant and controls for child's age and gender, and birth mother's and father's age. These parameters are not reported.

Standard errors are shown in italics, * indicates significance at $10 \%$ level, ${ }^{* *}$ indicates significance at $5 \%$ level, and ${ }^{* * *}$ significant at $1 \%$ level. 